\title{
Mechanism Underlying the Formation of Virtual Agglomeration of Creative Industries: Theoretical Analysis and Empirical Research
}

\author{
Xu Chen ${ }^{1} \mathbb{D}$, Chunhong Liu ${ }^{1}$, Changchun Gao ${ }^{1}$ and Yao Jiang ${ }^{2, *}$ \\ 1 Glorious Sun School of Business and Management, Donghua University, Shanghai 200051, China; \\ chenxu@mail.dhu.edu.cn (X.C.); chliu@dhu.edu.cn (C.L.); gcc19640428@163.com (C.G.) \\ 2 School of Management, Shanghai University of Engineering Science, Shanghai 201620, China \\ * Correspondence: JiangJoyce1992@163.com
}

Citation: Chen, X.; Liu, C.; Gao, C.; Jiang, Y. Mechanism Underlying the Formation of Virtual Agglomeration of Creative Industries: Theoretical Analysis and Empirical Research. Sustainability 2021, 13, 1637. https:// doi.org/10.3390/su13041637

Academic Editor: Isabel Novo-Corti Received: 11 January 2021

Accepted: 29 January 2021

Published: 3 February 2021

Publisher's Note: MDPI stays neutral with regard to jurisdictional claims in published maps and institutional affiliations.

Copyright: (c) 2021 by the authors. Licensee MDPI, Basel, Switzerland. This article is an open access article distributed under the terms and conditions of the Creative Commons Attribution (CC BY) license (https:// creativecommons.org/licenses/by/ $4.0 /)$.

\begin{abstract}
Industrial agglomeration serves as an effective model for developing the creative economy and manifests itself as the interdependence of creative subjects in geographical space. The traditional methods of resource agglomeration have undergone tremendous changes due to the development of digital technology. These transformations have given birth to a new organizational form of the virtual agglomeration of creative industries. The present work uses field interviews and grounded theoretical research methods to construct a theoretical model of this new organizational phenomenon. Questionnaire surveys and empirical testing using structural equation models are here combined to systematically analyze the formation mechanism of the virtual agglomeration of creative industries. The results show that digital technology, virtual platforms, digital creative talents, digitization of cultural resources, and government policies have driven the formation of the virtual agglomeration of creative industries. This has been achieved through network collaboration, freedom of participation, and trust guarantee mechanisms. The effect of emerging consumer demand on the virtual agglomeration of creative industries is not significant. In addition, the implications of this research are also considered and discussed.
\end{abstract}

Keywords: virtual agglomeration; creative industries; influencing factors; driving mechanisms

\section{Introduction}

The outbreak of the new coronavirus epidemic has accelerated offline creative activities to the cloud in an attempt to continuously meet the cultural needs of people. The creative community platform Xiaohongshu, for example, cooperated with teamLab and other art galleries to launch the Cloud View Exhibition event. The creative audio platform Himalaya invited more than 100 museums to set up radio stations to create the Sound Museum activity. The creative video community platform Bilibili has joined forces with the music agency Modern Sky to attract a large number of singers to the platform and hold an online music festival known as House Strawberry. Countless creative talents, creative users, creative enterprises, and relevant institutions rely on the network platform and can gather together to conduct creative activities including sharing ideas, creating content, negotiating projects, and providing product services. This agglomeration of creative industries based on virtual networks has overturned the traditional concept of geographic agglomeration and is called the virtual agglomeration of creative industries [1].

The research on virtual agglomeration originated from the COSME project funded by the European Union's SALFA program, which is also called Virtual Cluster and Ecluster [2-4]. The virtual agglomeration of creative industries based on the Internet and digital technology is a new form of industrial organization closely integrated online and offline. It completely subverts the traditional creative industry design, production, consumption, service, and other aspects and has important innovative significance for developing creative industries [5]. On the one hand, creative organizations can obtain creative 
inspiration, financial support, and talent support through crowd intelligence, crowdfunding, and crowdsourcing using the Internet [6]; transform in time creative inspiration into creative design; and finally form creative products or services [7]. On the other hand, creative organizations can have zero-distance contact with creative consumers based on online platforms, quickly capture the dynamics of creative demand, and accurately match creative products and services for consumers on time. The virtual agglomeration of creative industries is continuously forming and expanding rapidly because, in practice, the virtual agglomeration model has a positive effect on the development of creative industries. China's creative crowdsourcing service platform Yipin Witkey registered more than 22 million registered users from 2010 to 2020, opened more than 300 types of creative services, and successfully solved the creative needs of 9.8 million companies. Practice shows that a new type of model for creative industry development is emerging [8]. However, the management of this creative industry development model is not easy. There are still questions that need to be answered: Which factors promote the formation of the virtual agglomeration of creative industries? How do these factors drive the formation of the virtual agglomeration of creative industries?

A few studies address these issues, but the existing literature only summarizes the phenomenon of virtual agglomeration in a certain sub-industry of the creative industry. In research on influencing factors, Du et al. [9] took the virtual cluster of the animation industry as an example and believed that the environment-level influencing factors include market demand, network information infrastructure, and industrial policies; the industrylevel influencing factors include internal fixed organizations, internal system construction, internal cultural construction, network platform, and brand effect; the corporate-level influencing factors include the construction of internal-related information systems, the scale of the company, the ability to attract external capital, animation creativity, learning conversion capabilities, and the level of corporate manufacturing technology. Xie and Zang [10] took the network culture industry as an example and found that compared with traditional geographic agglomeration, the influence of netizens, technology, government, and other factors on the network culture industry ecosystem has changed. In research on the driving mechanism, $\mathrm{Li}$ and Quan [11] took the cultural travel industry as an example. They pointed out that the formation and operation mechanisms of the virtual agglomeration of the cultural travel industry mainly include precise operation mechanisms, virtual integration and community-based operation mechanisms, empowerment-based operation mechanisms, and global value network division mechanisms. The conclusions from the existing literature cannot systematically reveal the reasons for the formation of the virtual agglomeration of the creative industries from the overall level of the creative industries, and the internal mechanisms need to be deeply explored by combining qualitative and quantitative analysis methods.

Thus, it is important to consider the theoretical and practical aspects of the influencing factors and driving mechanisms for the formation of the virtual agglomeration of creative industries. For this reason, this study uses grounded theoretical research methods to explore the influencing factors and driving mechanisms of the formation of the virtual agglomeration of creative industries. It constructs a model of the formation mechanism of the virtual agglomeration of creative industries and conducts empirical testing combined with questionnaire surveys and structural equation models.

\section{Construction of the Theoretical Model}

The research focuses on identifying the factors that influence the formation of virtual agglomeration of creative industries and the mechanisms by which these factors exert said influence. However, the current research on the mechanism underlying the formation of the virtual agglomeration of creative industries is relatively sparse, and no mature theory or model has yet been developed. For this reason, in this work, the grounded theory method was used for exploratory analysis. Grounded theory was first proposed by American scholars Glaser B.G. and Strauss A.L. in the book "The Discovery of Grounded Theory: 
Strategies for Qualitative Research", published jointly in 1967 [12], and it has been widely used in management, psychology, sociology, pedagogy, and other research fields [13]. In its essence, it is a qualitative research method that generates theories from the bottom up based on empirical data, so it is particularly suitable studying issues for which there is little theoretical explanation. Here, the grounded theory method was used to construct a theoretical model of the mechanism underlying the formation of virtual agglomeration of creative industries by sequentially performing open coding, axial coding, and selective coding on text data. In the process of data analysis, the continuous comparison is used to refine and revise the theory until the theory is saturated (that is, the newly acquired data no longer make new contributions to the theoretical construction). On this basis, the hypothesis of this research will be proposed based on the constructed theoretical model.

\subsection{Interview Design and Implementation}

(1) Interview outline design and interviewee selection

First, this study set strict screening criteria for the interviewees to ensure the quality of the interview materials: (i) frequent participation in network creative activities; (ii) bachelor's degree or above; and (iii) researchers and employees in creative industries. On the premise of ensuring the theoretical saturation of the sample, 30 subjects were finally determined, including 16 males (53\%) and 14 females (47\%); 5 undergraduates (17\%), 8 masters (27\%), and $17 \mathrm{PhDs}(56 \%)$; 4 subjects were under 20 years old $(13 \%), 11$ were 21-30 years old ( $37 \%)$, and 15 were over 30 years old (50\%).

Second, the interview content was designed according to the research purpose, mainly centering on the driving factors and the process of the factors acting on the virtual agglomeration of creative industries. For example, increasingly more creative enterprises and consumers choose to gather on online platforms and engage in various creative activities. Why do you think this phenomenon occurs? What factors do you think have led to this phenomenon (virtual agglomeration of creative industries)? What do you think is the path of action of these factors?

(2) Interview implementation and data collection

One-to-one in-depth interviews were conducted with the selected interviewees according to the interview outline. Each interview lasted more than $60 \mathrm{~min}$, and a total of 30 people were interviewed. The interview process was recorded and 30 electronic records were transcribed after the interview. This study randomly selected 22 interview records for the following grounded theory coding and model construction; the remaining 8 interview records were used for theoretical saturation testing.

\subsection{Coding Analysis}

(1) Open coding

First, to avoid the subjective influence of the coder, the original words of the interviewee were directly used as the label and the initial concept was extracted from it. This study has a large number of initial concepts that are overlapping. This study therefore brings together the related concepts by decomposition, analysis, and refinement to achieve the categorization of the concept. After many sorting operations and analysis, initial concepts that appeared fewer than two times were eliminated, and 23 categories were finally established. Only one original statement corresponding to each initial concept is listed in Table 1 to save space. 
Table 1. Open coding results.

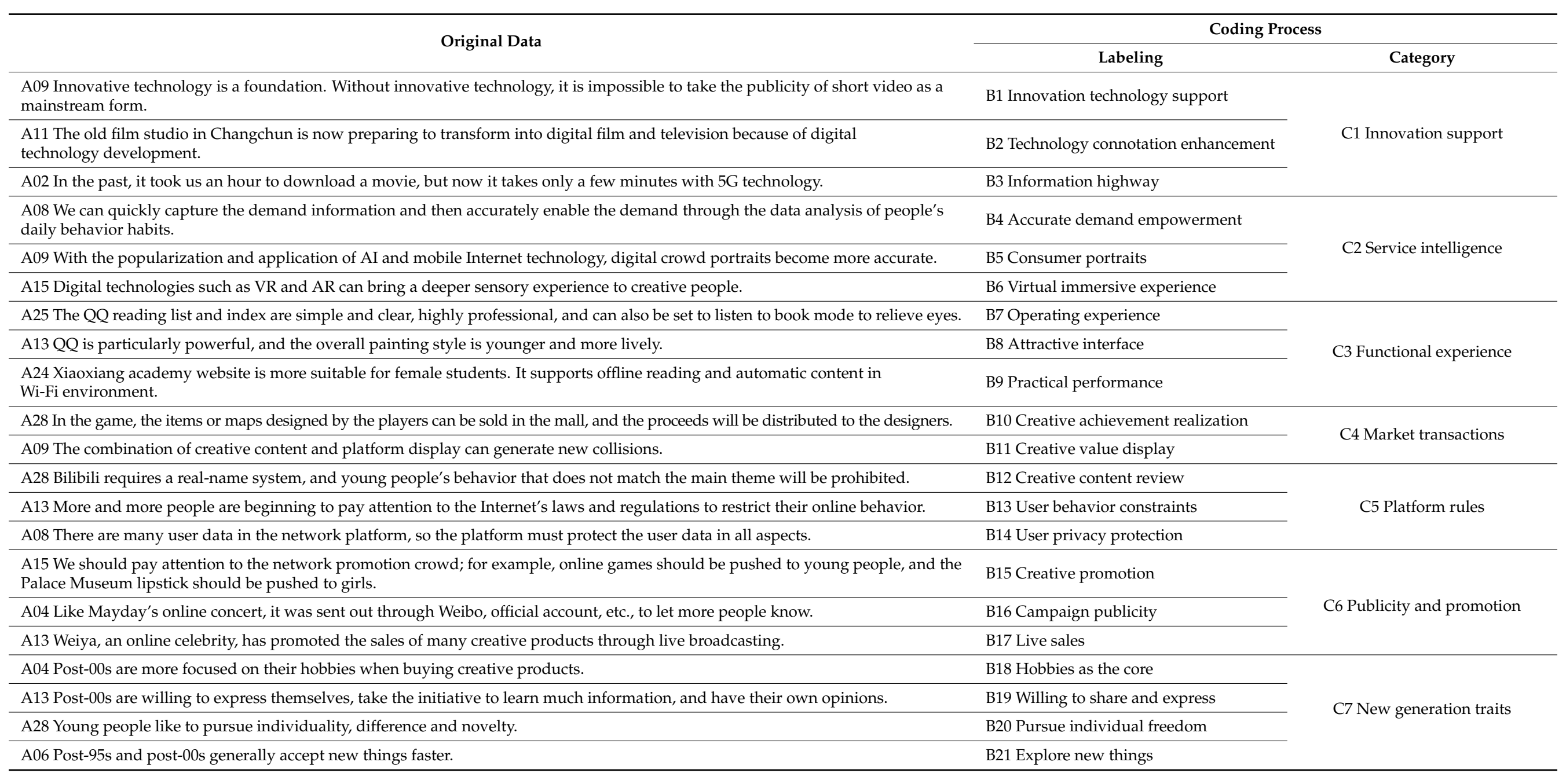


Table 1. Cont.

\section{Original Data}

A12 For most theater enthusiasts, viewing online may be a good bonus.

A07 I started using computers in the first grade of elementary school, and the Internet has become an inseparable part of my life. A08 Now most people's time is mostly fragmented.

A23 Economic and social development has increased spiritual and cultural needs and putting creative content on the Internet is also the satisfaction of spiritual needs.

A14 A creative person should be an all-around creative person who can combine creative trends with technological development.

A26 The digital creative industry is developing rapidly, but the gap of digital creative talents has become a bottleneck for development.

A13 Technological innovation has led to changes in the demand for talents in creative enterprises and has driven the transformation of digital creative talent training.

A02 The Hangzhou government has provided attractive policies for digital creative talents

A05 After digital creative development, historical and cultural resources can be understood by more people, which promotes the inheritance and development of culture.

A04 Digital cultural creativity can better and faster go abroad and promote cultural output.

A11 Culture is an essential thing. If the product lacks cultural connotation, it is just a simple commodity.

A01 For example, the Riverside Picture on Qingming Festival and the Old Summer Palace have been digitally restored, and derivative works developed, which further exerted their creative value.

A01 The digitization of cultural resources allows more people to experience the charm of outstanding culture and realize the sustainable use of cultural and creative resources.

A11 The government proposes new infrastructure tasks, which is a good way to boost the technical base.

A16 The business environment is like water, and the market subject is like fish. Therefore, the government must create a business environment conducive to the growth of fish.

A16 Intellectual property law is conducive to protecting creators' creative achievements and stimulating their enthusiasm for continuous creation.

A14 Cities like Shanghai, Beijing, and Shenzhen have issued various policies to purify the cultural and creative environment based on their own cultural development characteristics.

A16 The government network supervision department can conduct real-time supervision of network information to ensure network information security.

A06 The government provides various financial subsidies for the online gathering of creative small and mid-size enterprises

A16 To encourage creative enterprises to participate in online activities actively, the government has given different tax incentives.
B22 Channel facilitation

B23 Participants popularization

B24 Time fragmentation

B25 Pursue spiritualization

B26 Requirements for digital

creative talents

B27 Status of digital creative talent

B28 Digital creative talent training B29 Digital creative talent attracting

B30 Cultural heritage

B31 Creative output B32 Cultural implantation

B33 Creative product developmen

B34 Creative experience continuation

B35 New infrastructure

B36 Business environment optimization

B37 Intellectual property protection

B38 Network environment purification

B39 Network information security B40 Financial subsidy

B41 Tax incentives

\section{Category}

C8 Internet consumption habits

C9 Existing digital creative talents

C10 Potential digital creative talents

C11 Inheritance of digita cultural resources

C12 Utilization of digital cultural resources

13 Environment creation

C14 Network supervision

C15 Preferential support 
Table 1. Cont.

\section{Original Data}

A04 For example, Xiaomi provides all-around support for ecological chain companies and jointly defines, designs, and develops products with ecological chain companies.

A05 Consumers' creative needs can be distributed to creative companies by crowdsourcing on the platform, which improves collaboration and response speed between creative companies.

A04 Through the symbiosis of creative industries, the technological innovation cost of enterprises can be shared.

A02 For example, my customer suddenly has a new problem, and I can immediately report it to our manufacturer through the online platform.

A07 With the support of innovative technology, creative customization can be made more precise, such as three-dimensional tailored clothing.

A06 Flexible production meets the creative industry's development needs, which improves the efficiency of creative industry operations and makes resources more reasonably allocated.

A04 Through the symbiosis of creative industries, creative enterprises can enhance technological innovation's adaptability, shorten the innovation cycle, and reduce the risk of technological innovation.

A18 We can flexibly respond to the changes in the consumer market demand through virtual collaboration between industries.

A22 Wechat reading app uses a monthly charging system, which provides convenience for readers without purchasing each book separately.

A09 In the digital age, people are more willing to find suitable media to express their opinions freely.

A13 People can upload their original content on the network platform, which is easy to arouse people's sentiment.

A27 Barrage has truly transformed the Bilibili platform from a one-way video playback platform to a two-way emotional connection platform.

A02 Consumers can screen creative companies based on their credit records and reputation scores in cyberspace.

A01 Consumers can make consumption choices based on online evaluation information of creative products and services.

A18 The platform party shall promptly stop any behavior that violates the platform's regulations and may stop providing services to it when necessary.

A05 There are many online payment tools on the Internet, which are very safe and convenient to use.

A24 When entering the platform, the creative enterprise's authenticity must be reviewed, including the existing production and sales status and qualifications.

A15 The "e-commerce law of the people's Republic of China" has made provisions on illegal acts such as "brush praise", "big data kill", and "bidding ranking".

A14 For example, some representatives of the two sessions of the People's Congress of China this year put forward suggestions such as establishing the participants' integrity archives and formulating the "social credit law".

\section{Coding Proces}

\section{Labeling}

Category

B42 Industry chain participation

B43 Specialized production

C16 Value chain interaction B44 Cost savings

B45 Timely production feedback

B46 Creative product customization

C17 Flexible production

B47 Efficient resource utilization

B48 Reduce innovation risk

B49 Reduce market risk

B50 Flexible payment channels

B51 Free expression of opinions

B52 Content autonomous creation

B53 Community culture resonance

B54 Reputation rating

B55 Online evaluation

C21 Reputation evaluation

B56 Violation handling B57 Payment security

C22 Transaction guarantee

B58 Qualification review

B59 Laws and regulations

B60 Network integrity 
(2) Axial coding

Second, based on the internal connections and logical levels among 23 categories, this research formed nine main categories through cluster analysis, namely, "Digital technology", "Virtual platforms", "Emerging consumer demand", "Digital creative talents", and "Digitalization of cultural resources", "Government policies", "Network coordination", "Freedom of participation", and "Trust guarantee". The results of each main category and its corresponding subcategories are shown in Table 2.

Table 2. Axial coding results.

\begin{tabular}{ll}
\hline \multicolumn{1}{c}{ Main Category } & \multicolumn{1}{c}{ Subcategory } \\
\hline D1 Digital technology & C1 Innovation support; C2 Service intelligence; \\
D2 Virtual platforms & C3 Functional experience; C4 Market transactions; C5 Platform rules; C6 Publicity and promotion \\
D3 Emerging consumer demand & C7 New generation traits; C8 Internet consumption habits \\
D4 Digital creative talents & C9 Existing digital creative talents; C10 Potential digital creative talents \\
D5 Digitalization of cultural resources & C11 Inheritance of digital cultural resources; C12 Utilization of digital cultural resources \\
D6 Government policies & C13 Environment creation; C14 Network supervision; C15 Preferential support \\
D7 Network collaboration & C16 Value chain interaction; C17 Flexible production; C18 Risk sharing \\
D8 Freedom of participation & C19 Free entry; C20 Content co-creation \\
D9 Trust guarantee & C21 Reputation evaluation; C22 Transaction guarantee; C23 Violation constraint \\
\hline
\end{tabular}

(3) Selective coding

Third, this research uses selective coding analysis to refine the core category that can command other categories, and finally determines the core category as the virtual agglomeration of creative industries. The relationships between the core category and other categories are as follows: (i) The rapid development of digital technology accelerates the establishment of a cooperative innovation network among creative enterprises, which improves the innovation efficiency of creative enterprises. Creative enterprises can freely participate in the network production division, provide personalized products and services for users through safe and reliable cyberspace, and attract and drive more creative enterprises to gather on the Internet depending on the expertise of the companies. (ii) The virtual platform not only promotes the collaborative division of labor among creative enterprises through various platform functions, efficient information sharing, and convenient transaction process, but also reduces the entry threshold of creative enterprises based on the characteristics of openness and inclusiveness. At the same time, it protects and restricts the behaviors among enterprises through various rules and thus promotes the formation and stable development of the virtual agglomeration of creative industries. (iii) Consumers in the Internet age prefer to meet their own cultural needs through the Internet, thereby accelerating the concentration of creative enterprises and related institutions on the Internet platform. (iv) Digital creative talents directly participate in the production and operation of creative enterprises and form a cooperation network of mutual exchange and knowledge sharing, thus accelerating the formation of the virtual agglomeration of creative industries. (v) The digitization of cultural resources can make creative enterprises get rid of the physical space constraints, stimulate the creative inspiration and willingness of creative enterprises, and attract more creative enterprises to participate in them. (vi) The government can create a good atmosphere of trust for the network environment by adopting a series of policy measures that will help creative companies form an honest and trusting network relationship and attract creative companies to gather online.

In summary, the typical relationship structure among categories is determined as shown in Figure 1. 


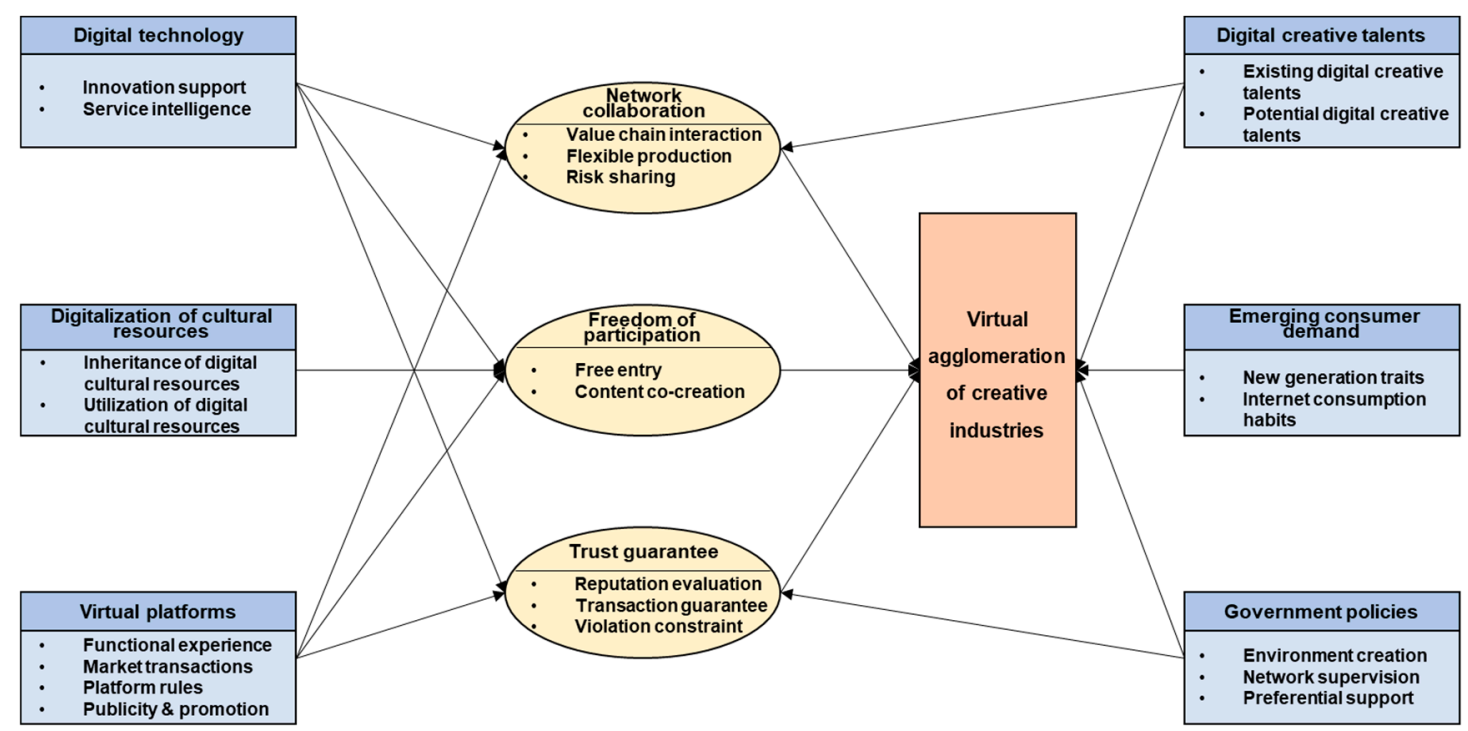

Figure 1. Typical relationship structure of the main categories.

\subsection{Theoretical Model and Hypothesis}

(1) Theoretical model construction

This research removes the subdivision dimensions of each category based on the previously described grounded theoretical analysis results. This helps to more clearly reflect and highlight the relationship between categories. Finally, it builds a theoretical model of the formation mechanism of creative industry virtual agglomeration as shown in Figure 2. As shown in Figure 2, the formation of virtual agglomeration of creative industries is affected by six factors according to the grounded theoretical analysis results: digital technology, virtual platforms, emerging consumer demand, digital creative talents, digitization of cultural resources, and government policies. In addition, the path of action of each factor is not completely consistent, and its effect is exerted through network coordination, freedom of participation, and trust guarantee mechanisms. Network collaboration refers to the behavior interaction between creative participants on the network; freedom of participation means that creative participants can freely enter the virtual space and engage in legal network economic activities; trust guarantee refers to the belief of universal reliability of the commitment or contract of the creative participants to others in the network cooperation, which is the basis for the stable cooperation between the main bodies.

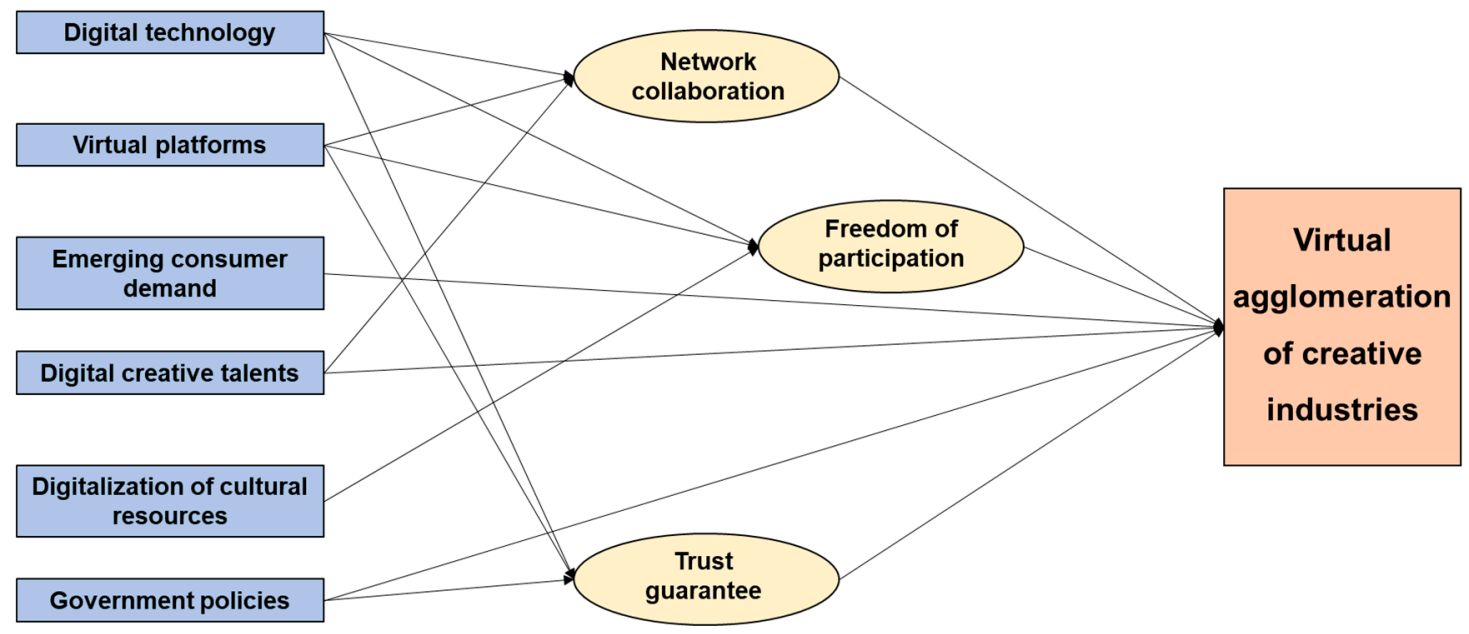

Figure 2. Theoretical model of the formation mechanism of creative industry virtual agglomeration. 
In addition, this study used the eight reserved interview records to test the theoretical saturation [14]. No new categories and logical relationships were found, which indicates that the theoretical model constructed by this research is saturated and complete.

(2) Model interpretation and research hypothesis

According to the theoretical model of the mechanism underlying the formation creative industry virtual agglomeration, each influencing factor's path of action is as follows:

1. The impact of digital technology on the formation of virtual agglomeration of creative industries. Grounded theoretical results show that digital technology has positively affected the formation of virtual clusters of creative industries through network collaboration, freedom of participation, and trust guarantee mechanisms. On the network coordination mechanism path, the rapid development of digital technology has accelerated the establishment of collaborative innovation networks between creative companies [15]. This has enabled creative companies to collaborate across regions, improve innovation efficiency, reduce production costs, and quickly meet consumer digital creative needs [16]. On the freedom of participation mechanism path, the activity boundary of creative enterprises can be widened with digital technology [17]. This can provide personalized products and services for consumers through creative customization, virtual experience, and transaction interaction [18], and helps attract and drive more creative enterprises to gather online. On the trust guarantee mechanism path, the in-depth application of digital technology can make real-time analysis of the traces of creative consumption, social interaction, and entertainment of users in the virtual space. This helps to obtain more abundant credit information sources [19], quickly assesses the credit rating of users, and provides early warnings of potential credit risk [20]. Therefore, it can improve the sense of identity and trust of participants in the virtual organization and promote the formation of virtual agglomeration of creative industries. Therefore, the following assumptions are proposed:

Hypothesis 1 (H1). The digital technology positively impacts the formation of the virtual agglomeration of creative industries through the network coordination mechanism.

Hypothesis 2 (H2). The digital technology positively impacts the formation of the virtual agglomeration of creative industries through the participation freedom mechanism.

Hypothesis 3 (H3). The digital technology positively impacts the formation of the virtual agglomeration of creative industries through the trust guarantee mechanism.

2. The impact of the virtual platforms on the formation of virtual agglomeration of creative industries. Grounded theoretical results show that virtual platforms actively influence the formation of virtual agglomeration of creative industries through network collaboration, freedom of participation, and trust guarantee mechanisms. On the network coordination mechanism path, the virtual platform promotes network collaboration between creative enterprises through diverse service functions [21], efficient information sharing [22], and convenient transaction procedures [23], thus reducing production costs of creative products and improving service efficiency [24-26]. On the freedom of participation mechanism path, the open and inclusive platform feature lowers the entry barrier for creative enterprises and drives a wider range of creative enterprises to gather on the platform [27]. On the trust guarantee mechanism path, there are complete reward and punishment rules on the virtual platform, which helps avoid the emergence of unethical and illegal behavior on the Internet ensures that the legal rights of creative enterprises are not infringed, and accelerates the formation of virtual agglomeration of creative industries [28]. Therefore, the following assumptions are proposed. 
Hypothesis 4 (H4). The virtual platforms positively impact the formation of the virtual agglomeration of creative industries through the network coordination mechanism.

Hypothesis 5 (H5). The virtual platforms positively impact the formation of the virtual agglomeration of creative industries through the participation freedom mechanism.

Hypothesis 6 (H6). The virtual platforms positively impact the formation of the virtual agglomeration of creative industries through the trust guarantee mechanism.

3. The impact of the emerging consumer demand on the formation of virtual agglomeration of creative industries. Grounded theoretical results show that the emerging consumer demand directly affects the formation of a virtual cluster of creative industries. The new generation group born in the period of the rapid development of the Internet has obvious differences from the previous generation in terms of thinking, values, and cognitive methods. The group members are more willing to pursue individuality, express themselves, and share knowledge on the Internet [29]. The borderless creative network environment provides a free and open space for the new generation of people and they are willing to gather on the network to organize and participate in various creative activities [30]. In addition, increasingly more people have begun to pursue spiritual and cultural experience and consumption as living standards have improved. Digital creative products that integrate online consumption and cultural creativity have met the changes in consumer demand of people and have generated a lot of consumer demand for the online development of creative industries, which has promoted the formation of a virtual agglomeration of creative industries [31]. Therefore, the following assumptions are proposed.

Hypothesis 7 (H7). The emerging consumer demand directly affects the formation of the virtual agglomeration of creative industries.

4. The influence of the digital creative talents on the formation of virtual agglomeration of creative industries. Grounded theory results show that digital creative talents can directly or indirectly influence the formation of virtual agglomeration of creative industries through the network collaboration mechanism. On the direct path, digital creative talents directly integrate their Internet operation concepts, digital skills, and business innovation thinking into the whole process of creative enterprise operations. This can accelerate the digital innovation process of enterprises and the construction of a creative network ecology, which ultimately helps to promote the formation of the virtual agglomeration of creative industries. On the network coordination mechanism path, digital creative talents have a strong sense of innovation and professional skills. They can rely on a collaborative network that includes close communication and knowledge sharing among digital creative talents. Digital creative talents can provide innovative digital creative designs, products, and services for the online business of creative enterprises [32] and promote the virtual agglomeration of creative industries. Therefore, the following assumptions are proposed:

Hypothesis 8 (H8). The digital creative talents directly affect the formation of the virtual agglomeration of creative industries.

Hypothesis 9 (H9). The digital creative talents positively impact the formation of the virtual agglomeration of creative industries through the network coordination mechanism.

5. The impact of the digitalization of cultural resources on the formation of the virtual agglomeration of creative industries. Grounded theoretical results show that the digitalization of cultural resources positively affects the formation of virtual agglom- 
eration of creative industries through the participation freedom mechanism. The digitization of cultural resources combines traditional cultural resources with advanced digital technologies such as virtual reality (VR), artificial reality (AR), artificial intelligence (AI), 5G, and others, which enlivens the static cultural resources originally displayed in museums and art galleries [33] and, at the same time, gives creative subjects the right to participate freely. Creative subjects can eliminate the physical space constraints and browse, learn, and use cultural resources online through the virtual network, to stimulate their creative inspiration [32]. In addition, under the authorization of digital cultural resources, creative enterprises can create and develop a series of digital creative derivative products, activate online R\&D, production, sales, and consumption ecology of creative industries. In this way, they can attract more creative enterprises to participate in these activities and promote the formation of the virtual agglomeration of creative industries. Therefore, the following assumptions are proposed.

Hypothesis 10 (H10). The digitalization of cultural resources positively affects the formation of the virtual agglomeration of creative industries through the participation freedom mechanism.

6. The impact of government policies on the formation of virtual clusters of creative industries. Grounded theoretical results show that government policies can directly or indirectly influence the formation of virtual agglomeration of creative industries through the network coordination mechanism. On the direct path, the government encourages the construction of new infrastructure, and formulates targeted financial subsidies and tax relief policies to guide the formation and development of the virtual agglomeration of creative industries [34]. On the trust guarantee mechanism path, the government takes various measures to effectively manage the illegal creative activities, protect the legitimate interests of creative participants, and create a good atmosphere of trust guarantee for online business [35]. Therefore, establishing a trust guarantee relationship between creative participants can accelerate the efficient flow of capital, information, and other elements in the virtual space [36] and greatly promote the formation of the virtual agglomeration of creative industries. Therefore, the following assumptions are proposed.

Hypothesis 11 (H11). The government policies directly affect the formation of the virtual agglomeration of creative industries.

Hypothesis 12 (H12). The government policies positively impact the formation of the virtual agglomeration of creative industries through the trust guarantee mechanism.

\section{Empirical Analysis}

3.1. Sample Collection

(1) Questionnaire design

Grounded theory analysis reveals that the formation mechanism model of creative industry virtual agglomeration involves six explanatory variables (digital technology, virtual platforms, emerging consumer demand, digital creative talents, digital cultural resources, and government policies), three intermediary variables (network collaboration, freedom of participation, and trust guarantee), and one explanatory variable (virtual agglomeration of creative industries). Here, several items were designed to measure these variables and formed the initial questionnaire by combining existing literature research and expert consultation.

Problems such as improper item setting and missing important items in the initial scale design can be encountered in this type of analysis. Two professors, four doctoral students, two master's candidates, and four business managers in creative fields were invited to participate in small-scale interviews to revise and improve the questionnaire 
item design. The scale items were further purified by a small sample test. The small sample test time was August 2020, and the test subjects were related practitioners in the creative industries. One hundred and eighty valid questionnaires were issued and collected. The reference standard purification scale item of factor loading was greater than 0.6 , the corrected item-total correlation (CITC) coefficient was greater than 0.4 , and the Cronbach $\alpha$ coefficient was greater than 0.7 [37]. This study finally retained 18 measurement items of explanatory variables, 9 measurement items of intermediate variables, and 3 measurement items of explained variables as shown in Table 3. Therefore, the formal questionnaire of this study consists of two parts: the first part contained the basic information of the interviewees, including gender, age, educational background, region, and work unit, with a total of five items; the second part addressed the formation mechanism of the virtual agglomeration of creative industries, using a Likert five-level scale where the score is 1-5.

Table 3. Measurement items.

\begin{tabular}{|c|c|c|}
\hline Variable & Item & Content \\
\hline \multirow{3}{*}{$\begin{array}{l}\text { Digital technology } \\
\text { (DT) }\end{array}$} & DT1 & The application of digital technology is conducive to the construction of the network platform. \\
\hline & DT2 & $\begin{array}{l}\text { The application of digital technology can help creative enterprises accurately identify the characteristics of } \\
\text { consumption demand. }\end{array}$ \\
\hline & DT3 & The application of digital technology can help creative enterprises provide personalized consumer services. \\
\hline \multirow{4}{*}{$\begin{array}{l}\text { Virtual platforms } \\
\text { (VP) }\end{array}$} & VP1 & Compared with offline, creative activities on online platforms have a better experience. \\
\hline & VP2 & Compared with offline, creative business transactions on online platforms are more efficient. \\
\hline & VP3 & The network platform has gradually formed its own perfect platform rules. \\
\hline & VP4 & Various publicity activities launched on the online platform are very attractive. \\
\hline \multirow{3}{*}{$\begin{array}{l}\text { Emerging consumer } \\
\text { demand } \\
(\mathrm{EC})\end{array}$} & EC1 & Young people like to organize various creative activities online. \\
\hline & EC2 & Young people like to participate in online creative activities. \\
\hline & EC3 & More and more consumers like to buy creative products through online channels. \\
\hline \multirow{3}{*}{$\begin{array}{l}\text { Digital creative talents } \\
\text { (DC) }\end{array}$} & DC1 & There are many talents currently engaged in online creative product development. \\
\hline & DC2 & The current creative talent-training system is perfect. \\
\hline & DC3 & There are many colleges and universities offering creativity-related majors. \\
\hline \multirow{3}{*}{$\begin{array}{l}\text { Digitalization of } \\
\text { cultural resources } \\
(\mathrm{DR})\end{array}$} & DR1 & Online creative product development is conducive to promoting cultural inheritance and protection. \\
\hline & DR2 & Online creative product forms can give consumers a unique cultural experience. \\
\hline & DR3 & Cultural and creative enterprises can obtain more benefits through online creative product development. \\
\hline \multirow{2}{*}{$\begin{array}{l}\text { Government policies } \\
(\mathrm{GP})\end{array}$} & GP1 & Government departments can effectively safeguard the legitimate online interests of creative enterprises. \\
\hline & GP2 & Government departments provide a wealth of support policies for online creative enterprises. \\
\hline \multirow{3}{*}{$\begin{array}{l}\text { Network collaboration } \\
\qquad(\mathrm{NC})\end{array}$} & NC1 & There are frequent exchanges and interactions between creative companies on the network platform. \\
\hline & NC2 & The production model of creative products on the network platform is more flexible. \\
\hline & NC3 & Creative companies on the online platform can share risks. \\
\hline \multirow{3}{*}{$\begin{array}{l}\text { Freedom of } \\
\text { participation } \\
(\mathrm{FP})\end{array}$} & FP1 & Both creative enterprises and consumers can easily and freely enter the network platform. \\
\hline & FP2 & Creative enterprises can carry out various forms of online creative activities. \\
\hline & FP3 & Consumers can participate in the creative product development process through the network platform. \\
\hline \multirow{3}{*}{$\begin{array}{l}\text { Trust guarantee } \\
\text { (TG) }\end{array}$} & TG1 & The credibility of creative enterprises on the online platform is easy to obtain. \\
\hline & TG2 & The online platform will supervise the entire process of creative product trading. \\
\hline & TG3 & Violations of creative enterprises can be dealt with in a timely manner by the network platform. \\
\hline \multirow{3}{*}{$\begin{array}{l}\text { Virtual agglomeration } \\
\text { of creative industries } \\
\text { (VA) }\end{array}$} & VA1 & At present, a large number of cultural and creative enterprises have settled on the network platform. \\
\hline & VA2 & $\begin{array}{l}\text { At present, a large number of cultural and creative-related supporting enterprises have settled on the } \\
\text { network platform. }\end{array}$ \\
\hline & VA3 & At present, a large number of cultural and creative talents are pouring into the network platform. \\
\hline
\end{tabular}

\section{(2) Data collection}

Strict screening was conducted on the distribution area, method, and target of the questionnaire to ensure the validity of the data. The distribution area covered by the questionnaire covered most of the provinces and cities in China and some places overseas; for distribution, two forms were selected, namely Questionnaire Star and WeChat Link, and used to invite relevant personnel to complete in a way that ensured the integrity and reliability of the data; in terms of distribution objects, design filter items such as "Have you heard of cultural and creative industries?" and "Did you participate in creative activities or purchase creative products on the Internet?" were used to select those who met the requirements. The questionnaire was issued on September 2020; 410 questionnaires were 
obtained. After excluding invalid questionnaires, 357 valid questionnaires were finally obtained, and the effective rate was $87.1 \%$.

The descriptive statistics of the respondents' basic information are shown in Table 4. Women made up $64.99 \%$ of respondents and men $35.01 \%$. Most of them were young and middle-aged: 21 to 40 years old was the primary age group, accounting for $67.79 \%$; Most of them had a bachelor's degree or higher, accounting for $86 \%$. In terms of regional distribution, respondents were scattered across 21 provinces and cities in China and three overseas areas. In terms of the work unit, universities or research institutes and enterprises accounted for a relatively high proportion, accounting for $44.26 \%$ and $33.05 \%$, respectively. The respondents' basic information reflects the participants' professionalism and ensures the questionnaire research results' validity.

Table 4. Descriptive statistics of the respondents' basic information.

\begin{tabular}{|c|c|c|c|}
\hline & Item & Frequency & Percentage \\
\hline \multirow[b]{2}{*}{ Gender } & Male & 125 & $35.01 \%$ \\
\hline & Female & 232 & $64.99 \%$ \\
\hline \multirow{6}{*}{ Age } & Under 20 years old & 15 & $4.20 \%$ \\
\hline & 21 to 30 years old & 170 & $47.62 \%$ \\
\hline & 31 to 40 years old & 72 & $20.17 \%$ \\
\hline & 41 to 50 years old & 58 & $16.25 \%$ \\
\hline & 51 to 60 years old & 35 & $9.80 \%$ \\
\hline & Over 60 years old & 7 & $1.96 \%$ \\
\hline \multirow{5}{*}{ Education } & High school or below & 22 & $6.16 \%$ \\
\hline & College degree & 28 & $7.84 \%$ \\
\hline & Bachelor's degree & 118 & $33.05 \%$ \\
\hline & Master's degree & 135 & $37.82 \%$ \\
\hline & Doctoral degree & 54 & $15.13 \%$ \\
\hline \multirow{22}{*}{ Region } & Shanghai & 161 & $45.10 \%$ \\
\hline & Jilin & 49 & $13.73 \%$ \\
\hline & Anhui & 25 & $7.00 \%$ \\
\hline & Jiangsu & 16 & $4.48 \%$ \\
\hline & Beijing & 15 & $4.20 \%$ \\
\hline & Heilongjiang & 14 & $3.92 \%$ \\
\hline & Zhejiang & 14 & $3.92 \%$ \\
\hline & Sichuan & 7 & $1.96 \%$ \\
\hline & Tianjin & 7 & $1.96 \%$ \\
\hline & Inner Mongolia & 7 & $1.96 \%$ \\
\hline & Shandong & 6 & $1.68 \%$ \\
\hline & Fujian & 6 & $1.68 \%$ \\
\hline & Guangdong & 5 & $1.40 \%$ \\
\hline & Hubei & 5 & $1.40 \%$ \\
\hline & Hunan & 4 & $1.12 \%$ \\
\hline & Henan & 4 & $1.12 \%$ \\
\hline & Liaoning & 3 & $0.84 \%$ \\
\hline & Shanxi & 2 & $0.56 \%$ \\
\hline & Jiangxi & 2 & $0.56 \%$ \\
\hline & Shaanxi & 1 & $0.28 \%$ \\
\hline & Hainan & 1 & $0.28 \%$ \\
\hline & Overseas area & 3 & $0.84 \%$ \\
\hline \multirow{5}{*}{ Work unit } & University or research institute & 158 & $44.26 \%$ \\
\hline & Enterprise & 118 & $33.05 \%$ \\
\hline & Government department & 28 & $7.84 \%$ \\
\hline & Industry Association or Intermediary Organization & 7 & $1.96 \%$ \\
\hline & Other & 46 & $12.89 \%$ \\
\hline \multicolumn{2}{|r|}{ Total } & 357 & $100 \%$ \\
\hline
\end{tabular}

\subsection{Data Analysis}

Partial least squares structural equation modeling (PLS-SEM) is suitable for exploratory research, especially to test some unproven hypotheses in the existing literature [38]. It is more flexible in dealing with multi-faceted complex structure models compared with SEM [39]. Our research is an exploratory analysis of the virtual agglomeration of creative industries. The structural equation model has multiple dimensions. PLS-SEM was 
here used to verify the model and hypothesis. The analysis process of PLS-SEM is based on smart PLS 3.0 software, which includes two steps: the measurement model test and structural model test $[40,41]$.

(1) Measurement model test

Reliability reflects the consistency of construct measurement items. It can be defined by Cronbach's $\alpha$ and combined reliability (CR) scores. The Cronbach's $\alpha$ and CR scores of all constructs were greater than 0.7 , which indicates good reliability [42] as shown in Table 5.

Table 5. Reliability and aggregate validity test results.

\begin{tabular}{|c|c|c|c|c|c|}
\hline Construct & Item & Loading & AVE & Cronbach's $\alpha$ & CR \\
\hline \multirow{3}{*}{$\begin{array}{l}\text { Digital technology } \\
\text { (DT) }\end{array}$} & DT1 & 0.913 & \multirow{3}{*}{0.855} & \multirow{3}{*}{0.915} & \multirow{3}{*}{0.947} \\
\hline & DT2 & 0.935 & & & \\
\hline & DT3 & 0.927 & & & \\
\hline \multirow{4}{*}{$\begin{array}{l}\text { Virtual platforms } \\
\text { (VP) }\end{array}$} & VP1 & 0.720 & \multirow{4}{*}{0.558} & \multirow{4}{*}{0.909} & \multirow{4}{*}{0.834} \\
\hline & VP2 & 0.798 & & & \\
\hline & VP3 & 0.760 & & & \\
\hline & VP4 & 0.705 & & & \\
\hline \multirow{3}{*}{$\begin{array}{l}\text { Emerging consumer demand } \\
\text { (EC) }\end{array}$} & EC1 & 0.926 & \multirow{3}{*}{0.780} & \multirow{3}{*}{0.856} & \multirow{3}{*}{0.913} \\
\hline & EC2 & 0.921 & & & \\
\hline & EC3 & 0.796 & & & \\
\hline \multirow{3}{*}{$\begin{array}{l}\text { Digital creative talents } \\
\text { (DC) }\end{array}$} & DC1 & 0.848 & \multirow{3}{*}{0.728} & \multirow{3}{*}{0.814} & \multirow{3}{*}{0.889} \\
\hline & DC2 & 0.848 & & & \\
\hline & DC3 & 0.864 & & & \\
\hline \multirow{3}{*}{$\begin{array}{l}\text { Digitalization of cultural resources } \\
\text { (DR) }\end{array}$} & DR1 & 0.852 & \multirow{3}{*}{0.706} & \multirow{3}{*}{0.792} & \multirow{3}{*}{0.878} \\
\hline & DR2 & 0.819 & & & \\
\hline & DR3 & 0.849 & & & \\
\hline \multirow{2}{*}{$\begin{array}{l}\text { Government policies } \\
\text { (GP) }\end{array}$} & GP1 & 0.920 & \multirow{2}{*}{0.854} & \multirow{2}{*}{0.829} & \multirow{2}{*}{0.921} \\
\hline & GP2 & 0.928 & & & \\
\hline \multirow{3}{*}{$\begin{array}{l}\text { Network collaboration } \\
\text { (NC) }\end{array}$} & $\mathrm{NC1}$ & 0.907 & \multirow{3}{*}{0.748} & \multirow{3}{*}{0.831} & \multirow{3}{*}{0.899} \\
\hline & NC2 & 0.856 & & & \\
\hline & NC3 & 0.831 & & & \\
\hline \multirow{3}{*}{$\begin{array}{l}\text { Freedom of participation } \\
\text { (FP) }\end{array}$} & FP1 & 0.870 & \multirow{3}{*}{0.765} & \multirow{3}{*}{0.846} & \\
\hline & FP2 & 0.888 & & & 0.907 \\
\hline & FP3 & 0.865 & & & \\
\hline & TG1 & 0.898 & & & \\
\hline Trust guarantee & TG2 & 0.906 & 0.810 & 0.883 & 0.927 \\
\hline & TG3 & 0.896 & & & \\
\hline & VA1 & 0.931 & & & \\
\hline Virtual agglomeration of creative industries & VA2 & 0.937 & 0.846 & 0.742 & 0.943 \\
\hline & VA3 & 0.890 & & & \\
\hline
\end{tabular}

Validity reflects the validity of construct measurement items. The evaluation of validity includes aggregation validity and discrimination validity. In the aggregation validity test, each factor loading was greater than $0.7[43,44]$ and the average variance extraction (AVE) was greater than 0.5 [45] as shown in Table 5, which indicates that the construct had sufficient aggregation validity [42]. In addition, in the discriminative validity test, the square root of the AVE of each construct was greater than its Pearson correlation coefficient with other constructs (Table 6), which indicates that the measurement model had good discriminative validity $[46,47]$. 
Table 6. Discriminative validity test results.

\begin{tabular}{|c|c|c|c|c|c|c|c|c|c|c|}
\hline $\begin{array}{l}\text { Correlation Coefficient } \\
\text { and Square Root of AVE }\end{array}$ & DT & VP & EC & DC & DR & GP & NC & $\mathbf{F P}$ & TG & VA \\
\hline DT & 0.925 & & & & & & & & & \\
\hline VP & 0.420 & 0.747 & & & & & & & & \\
\hline EC & 0.443 & 0.635 & 0.883 & & & & & & & \\
\hline DC & 0.265 & 0.548 & 0.361 & 0.853 & & & & & & \\
\hline DR & 0.501 & 0.628 & 0.529 & 0.446 & 0.840 & & & & & \\
\hline GP & 0.345 & 0.519 & 0.379 & 0.542 & 0.472 & 0.924 & & & & \\
\hline $\mathrm{NC}$ & 0.471 & 0.645 & 0.500 & 0.559 & 0.570 & 0.617 & 0.865 & & & \\
\hline $\mathrm{FP}$ & 0.588 & 0.540 & 0.449 & 0.359 & 0.584 & 0.447 & 0.582 & 0.874 & & \\
\hline TG & 0.350 & 0.653 & 0.354 & 0.487 & 0.496 & 0.528 & 0.536 & 0.518 & 0.900 & \\
\hline VA & 0.403 & 0.556 & 0.382 & 0.549 & 0.477 & 0.450 & 0.596 & 0.564 & 0.623 & 0.920 \\
\hline
\end{tabular}

Note: The diagonal is the square root of AVE, and the lower triangle is the Pearson correlation coefficient.

Exploratory factor analysis was conducted based on the Harman single factor method to evaluate the severity of the common method bias of the data [48]. In the exploratory factor analysis results, the Kaiser-Meyer-Olkin (KMO) value was 0.922 (greater than 0.7), and the significance level of Bartlett's ball test was less than 0.05, which indicated that exploratory factor analysis was suitable. Furthermore, the principal component analysis method was used to extract the characteristic roots with a characteristic value greater than 1. Six factors were extracted without rotation, and the cumulative variance contribution rate was $68.552 \%$ (greater than $60 \%$ ). The first principal component explained $41.528 \%$ of the variance, which was less than $50 \%$ of the recommended value. Therefore, there was no significant common method bias in the data.

(2) Structural model test

First, the model explanatory power indicators $R^{2}$ and $Q^{2}$ were used for model testing and evaluation before the path analysis. The $R^{2}$ values for the four dimensions of network collaboration, participation freedom, trust guarantee, and virtual agglomeration of creative industries were $0.520,0.486,0.476$, and 0.547 , respectively, and the corresponding constructs $Q^{2}$ were all greater than zero, which indicates that the explanatory power and predictive power of the model are both stronger [44,49].

Second, the model was tested using the Bootstrapping algorithm $(n=5000)$ to test the path coefficients of the structural equation. The results are shown in Figure 3 and Table 7.

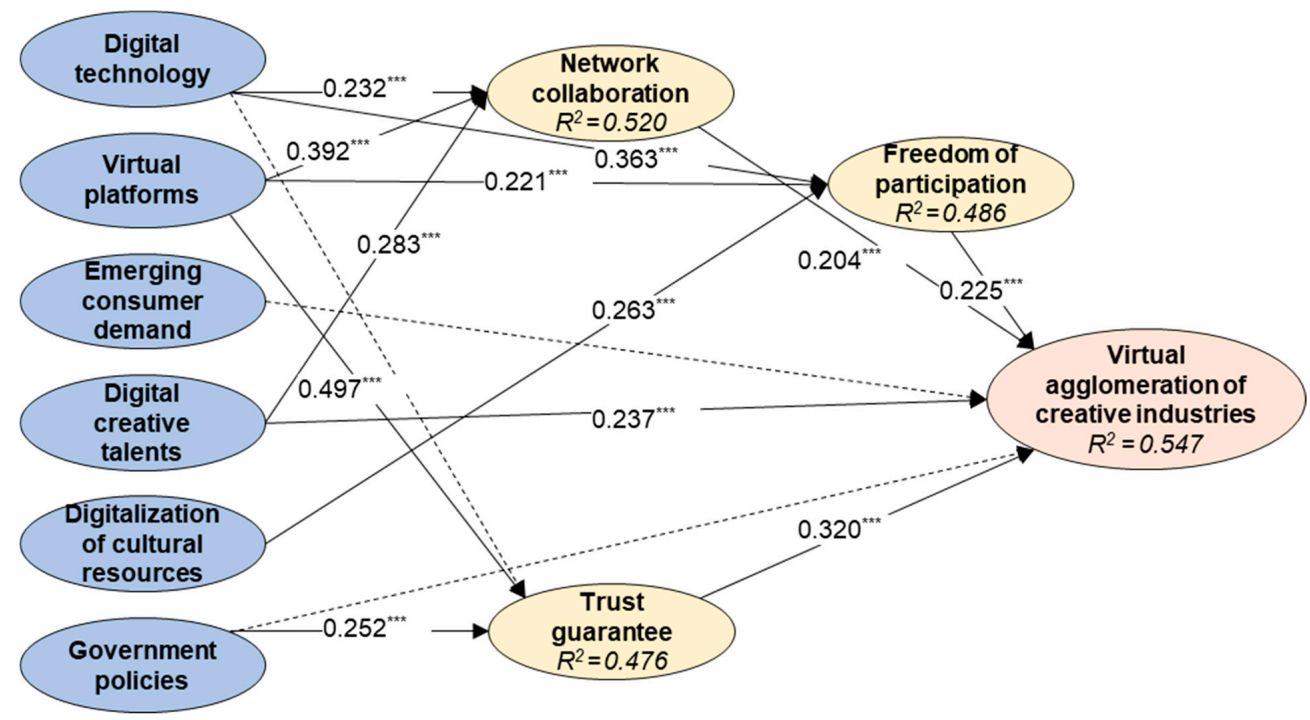

Figure 3. Model standardized path coefficients and test results. Note: ${ }^{*} p$ value $<0.05,{ }^{* *} p$ value $<0.01$, *** $p$ value $<0.001$; the dotted arrow indicates that the path is not established. 
Table 7. Model path analysis.

\begin{tabular}{|c|c|c|c|c|c|}
\hline Model Path & Estimates & Mean & SD & $t$ Values & $p$ Values \\
\hline $\mathrm{DT} \rightarrow \mathrm{NC}$ & 0.232 & 0.232 & 0.042 & 5.492 & $* * *$ \\
\hline $\mathrm{DT} \rightarrow \mathrm{FP}$ & 0.363 & 0.363 & 0.046 & 7.955 & $* * *$ \\
\hline $\mathrm{DT} \rightarrow \mathrm{TG}$ & 0.055 & 0.055 & 0.041 & 1.356 & 0.175 \\
\hline $\mathrm{VP} \rightarrow \mathrm{NC}$ & 0.392 & 0.393 & 0.048 & 8.186 & $* * *$ \\
\hline $\mathrm{VP} \rightarrow \mathrm{FP}$ & 0.221 & 0.222 & 0.054 & 4.104 & $* * *$ \\
\hline $\mathrm{VP} \rightarrow \mathrm{TG}$ & 0.497 & 0.499 & 0.044 & 11.226 & $* * *$ \\
\hline $\mathrm{EC} \rightarrow \mathrm{VA}$ & 0.009 & 0.011 & 0.043 & 0.202 & 0.840 \\
\hline $\mathrm{DC} \rightarrow \mathrm{NC}$ & 0.283 & 0.283 & 0.045 & 6.252 & $* * *$ \\
\hline $\mathrm{DC} \rightarrow \mathrm{VA}$ & 0.237 & 0.236 & 0.049 & 4.813 & $* * *$ \\
\hline $\mathrm{DR} \rightarrow \mathrm{PF}$ & 0.263 & 0.265 & 0.064 & 4.110 & $* * *$ \\
\hline $\mathrm{GP} \rightarrow \mathrm{TG}$ & 0.252 & 0.251 & 0.051 & 4.946 & $* * *$ \\
\hline $\mathrm{GP} \rightarrow \mathrm{VA}$ & -0.077 & -0.077 & 0.058 & 1.331 & 0.183 \\
\hline $\mathrm{NC} \rightarrow \mathrm{VA}$ & 0.204 & 0.205 & 0.059 & 3.464 & $* * *$ \\
\hline $\mathrm{PF} \rightarrow \mathrm{VA}$ & 0.225 & 0.223 & 0.050 & 4.493 & $* * *$ \\
\hline $\mathrm{TG} \rightarrow \mathrm{VA}$ & 0.320 & 0.319 & 0.058 & 5.528 & $* * *$ \\
\hline
\end{tabular}

Finally, the specific intermediary paths formed by the virtual agglomeration of creative industries were tested for different influencing factors according to the research hypothesis. The results are shown in Table 8.

Table 8. Mediation effect analysis.

\begin{tabular}{cccccc}
\hline Intermediary Path & Estimates & Mean & SD & $t$ Values & $p$ Values \\
\hline $\mathrm{DT} \rightarrow \mathrm{NC} \rightarrow \mathrm{VA}$ & 0.047 & 0.048 & 0.016 & 2.915 & $* *$ \\
$\mathrm{DT} \rightarrow \mathrm{FP} \rightarrow \mathrm{VA}$ & 0.082 & 0.081 & 0.022 & 3.766 & $* * *$ \\
$\mathrm{DT} \rightarrow \mathrm{TG} \rightarrow \mathrm{VA}$ & 0.018 & 0.018 & 0.014 & 1.291 & 0.197 \\
$\mathrm{VP} \rightarrow \mathrm{NC} \rightarrow \mathrm{VA}$ & 0.080 & 0.080 & 0.024 & 3.319 & $* * *$ \\
$\mathrm{VP} \rightarrow \mathrm{FP} \rightarrow \mathrm{VA}$ & 0.050 & 0.049 & 0.016 & 3.141 & $* *$ \\
$\mathrm{VP} \rightarrow \mathrm{TG} \rightarrow \mathrm{VA}$ & 0.159 & 0.159 & 0.032 & 4.940 & $* * *$ \\
$\mathrm{DC} \rightarrow \mathrm{NC} \rightarrow \mathrm{VA}$ & 0.058 & 0.058 & 0.021 & 2.791 & $* *$ \\
$\mathrm{DR} \rightarrow \mathrm{FP} \rightarrow \mathrm{VA}$ & 0.059 & 0.059 & 0.019 & 3.052 & $* *$ \\
$\mathrm{GP} \rightarrow \mathrm{TG} \rightarrow \mathrm{VA}$ & 0.081 & 0.081 & 0.023 & 3.503 & $* * *$ \\
\hline Note: ${ }^{*} p$ value $<0.05,{ }^{* *} p$ value $<0.01,{ }^{* * *} p$ value $<0.001$. & & &
\end{tabular}

\section{Results and Discussion}

The test passing conditions for the hypothesis can be obtained as shown in Table 9 once the previously mentioned path analysis and mediation effect tests have been performed. The specific test results are as follows: (i) digital technology can significantly promote the formation of the virtual agglomeration of creative industries through the intermediary effect of network coordination mechanism and participation freedom mechanism. The path coefficients are 0.047 and 0.082 , respectively, for the network coordination mechanism and participation freedom mechanism. $\mathrm{H} 1$ and $\mathrm{H} 2$ were verified. However, digital technology did not significantly promote the formation of the virtual agglomeration of creative industries through the intermediary role of the trust guarantee mechanism. H3 was not verified. (ii) The virtual platforms can significantly promote the formation of the virtual agglomeration of creative industries through the mediation of network coordination mechanism, participation freedom mechanism, and trust guarantee mechanism. The path coefficients were $0.080,0.050$, and 0.159 , respectively, for these mechanisms. $\mathrm{H} 4, \mathrm{H} 5$, and $\mathrm{H} 6$ were verified. (iii) The direct effect of emerging consumer demand on the formation of the virtual agglomeration of creative industries was not significant. H7 was not verified. (iv) Digital creative talents can directly and significantly promote the formation of the virtual agglomeration of creative industries and significantly impact the formation of the virtual agglomeration of creative industries through the intermediary role of network coordination mechanism. The path coefficients were 0.237 and 0.058 , respectively. $\mathrm{H} 8$ and 
H9 were verified. (v) The digitization of cultural resources can significantly promote the formation of the virtual agglomeration of creative industries through the intermediary effect of freedom of participation mechanism. The path coefficient was 0.059 , and H10 was verified. (vi) Government policies can significantly promote the formation of the virtual agglomeration of creative industries through the intermediary effect of the trust guarantee mechanism. The path coefficient was 0.081 , and $\mathrm{H} 12$ was verified. However, its direct effect was not significant; H11 was not verified.

Table 9. Hypothesis test results.

\begin{tabular}{lc}
\hline \multicolumn{1}{c}{ Hypothesis } & Result \\
$\mathrm{H} 1: \mathrm{DT} \rightarrow \mathrm{NC} \rightarrow \mathrm{VA}$ & Accepted \\
$\mathrm{H} 2: \mathrm{DT} \rightarrow \mathrm{FP} \rightarrow \mathrm{VA}$ & Accepted \\
$\mathrm{H} 3: \mathrm{DT} \rightarrow \mathrm{TG} \rightarrow \mathrm{VA}$ & Not accepted \\
$\mathrm{H} 4: \mathrm{VP} \rightarrow \mathrm{NC} \rightarrow \mathrm{VA}$ & Accepted \\
$\mathrm{H} 5: \mathrm{VP} \rightarrow \mathrm{FP} \rightarrow \mathrm{VA}$ & Accepted \\
$\mathrm{H} 6: \mathrm{VP} \rightarrow \mathrm{TG} \rightarrow \mathrm{VA}$ & Accepted \\
$\mathrm{H} 7: \mathrm{EC} \rightarrow \mathrm{VA}$ & Not accepted \\
$\mathrm{H} 8: \mathrm{DC} \rightarrow \mathrm{VA}$ & Accepted \\
$\mathrm{H} 9: \mathrm{DC} \rightarrow \mathrm{NC} \rightarrow \mathrm{VA}$ & Accepted \\
$\mathrm{H} 10: \mathrm{DR} \rightarrow \mathrm{FP} \rightarrow \mathrm{VA}$ & Accepted \\
$\mathrm{H} 11: \mathrm{GP} \rightarrow \mathrm{VA}$ & Not accepted \\
$\mathrm{H} 12: \mathrm{GP} \rightarrow \mathrm{TG} \rightarrow \mathrm{VA}$ & Accepted \\
\hline
\end{tabular}

The test results for the hypotheses described earlier showed that digital technology, virtual platforms, digital creative talents, digital cultural resources, and government policies can significantly promote the formation of the virtual agglomeration of creative industries through network collaboration, participation freedom, and trust guarantee mechanisms. The driving effect for each factor was different. Thus, it was necessary to further compare the size of the driving effects of the various factors. This study separately calculated the direct effects, indirect effects, and total effects of promoting the formation of the virtual agglomeration of creative industries and the results are shown in Table 10.

Table 10. Effect of driving the formation of the virtual agglomeration of creative industries.

\begin{tabular}{cccc}
\hline Influence Factors & Direct Effect & Indirect Effect & Total Effect \\
\hline $\mathrm{DT} \rightarrow$ VA & & 0.129 & 0.129 \\
$\mathrm{VP} \rightarrow$ VA & & 0.288 & 0.288 \\
$\mathrm{DC} \rightarrow$ VA & 0.237 & 0.058 & 0.295 \\
$\mathrm{DR} \rightarrow$ VA & & 0.059 & 0.059 \\
$\mathrm{GP} \rightarrow$ VA & & 0.081 & 0.081 \\
\hline
\end{tabular}

Digital creative talents had a total effect of 0.295 (direct effect 0.237 and indirect effect 0.058 ) and played the most important role in the formation of the virtual agglomeration of creative industries when the five influencing factors were examined; virtual platform had the second highest impact, with a total effect of 0.288 , and no direct effect; digital technology, government policies, and digitization of cultural resources only had indirect effects, with values of $0.129,0.081$, and 0.059 , respectively.

\section{Conclusions and Limitations}

\subsection{Theoretical Implications}

The research described in this study explores the benefits of the phenomenon of virtual agglomeration of creative industries. Grounded theory research methods were used to construct a theoretical model of the formation mechanism of the virtual agglomeration of creative industries. Furthermore, the structural equation method, which was based on a questionnaire survey, was used to test the theoretical model and determine the factors 
influencing the virtual agglomeration of creative industries and its driving mechanisms. The specific conclusions are described here.

First, the factors driving the formation of virtual agglomeration of creative industries include digital technology, virtual platforms, digital creative talents, digitization of cultural resources, and government policies. The impact of digital creative talents is the most significant driver, followed by the virtual platforms, digital technology, and government policy factors [50]. The digitization of cultural resources has the lowest impact.

Second, the driving mechanism of various factors on forming virtual agglomeration of creative industries includes three major mechanisms: network coordination, freedom of participation, and trust guarantee. Digital technology has an indirect effect through network collaboration and freedom of participation; the virtual platforms have an indirect effect through network collaboration, freedom of participation, and trust guarantee; digital creative talents not only directly promote the formation of virtual agglomeration of creative industries, but also have an indirect impact through the mediation of network collaboration; the digitization of cultural resources exerts an indirect driving effect through freedom to participate; government policies produce an indirect driving effect through trust guarantee.

Third, the emerging consumer demand factor is not significant in promoting the formation of the virtual agglomeration of creative industries. One possible reason for this is that in the initial stage of the formation of virtual agglomeration, the scale of creative consumption on the platform is minimal [51,52]. The platform therefore needs to adopt huge subsidies and preferential policies to attract emerging consumer groups to gather there [53]. Hence, the influence of emerging consumer demand on the formation of creative virtual agglomeration is not clear. However, as the virtual agglomeration of creative industries enters a mature period and emerging consumer demand continues to expand, the effect of this factor on virtual agglomeration may become more obvious [51].

\subsection{Practical Implications}

The conclusions drawn from this research can provide the necessary enlightenment to promote the formation and development of virtual agglomeration of creative industries in practice.

First, digital technology is a critical force in promoting the virtual development of creative industries. It is necessary to actively promote the digital integration of various fields of creative industries, create the core for the digital, networked, and intelligent development of creative industries, realize the upgrading and innovation of the whole industrial chain, and promote the improvement of product quality and service experience with higher efficiency [54]. In addition, it is necessary strengthen the research and development of generic technologies, algorithms, and software for creative industries, establish a network cooperation system of interconnection between upstream and downstream of the industrial chain, and build an excellent digital industrial ecology for the virtual agglomeration of creative industries [55].

Second, the virtual platform is an essential carrier for the virtual development of creative industries. It is necessary to continuously improve its intellectual service level with more advanced intelligent algorithms [56], perfect platform rules [57], and humanized service functions to realize more accurate information matching, network collaboration, and value transactions between creative subjects [58]. Researchers should rely on virtual platforms to vigorously develop new models such as crowdsourcing, cloud outsourcing, and platform subcontracting [59] to promote the efficient utilization and value play of creative resources, accelerate the realization of the integrated development of the entire creative industries, and promote the formation of virtual agglomeration of creative industries.

Third, digital creative talents are the first resource for the virtual development of creative industries. It is necessary to reach a breakthrough to solve the current shortage in the supply of talent and insufficient creative potential [60]. In terms of improving the supply of talent, the government, universities, and enterprises should establish comprehensive measures from a digital creative talent project plan including talent introduction 
mechanisms and talent training model as well as other measures to continue talent transfusion for the virtual agglomeration of creative industries [61]. As far as talent creativity is concerned, society should expand the tolerance for digital creative talents, create a more relaxed creative atmosphere, and continue to activate their creative potential [32], thereby promoting the virtual agglomeration of creative industries to a deeper level.

Fourth, excellent digital creative products and services are inseparable from the core of digital cultural resources [62]. It is necessary to encourage new designs and new technologies to transform traditional excellent cultural resources and integrate contemporary aesthetics and values into them, which will help give traditional cultural resources new life [63]. Researchers should advocate the open sharing of digital cultural resources in virtual spaces so that creative organizations have the opportunity to create various digital creative boutiques under authorization, activate industrial $R \& D$, production, sales, and consumption chains [64], and promote the virtual agglomeration of creative industries.

Fifth, the government plays a vital role as guide, maintainer, and arbitrator in the virtual network space, which means that the government needs to keep pace with the times and realize the digital transformation of governance [50]. It is necessary to actively build a government with digital system integration, sharing information, data collaboration, and intelligent service [65]. The government should innovate the policy service system, and continue to guide the digital innovation of creative industries, maintain the order of the network economy, ensure transaction security, protect network property rights, crack down on internet violations, and create a virtual environment of fairness and mutual trust for the virtual cluster of creative industries [66].

\subsection{Limitations}

These findings provide significant guidance for forming a virtual agglomeration of creative industries in theory and practice but limitations remain. First, this study uses in-depth interviews and questionnaire survey methods to collect sample data. The sample results may be affected by the subjective influence of the interviewees. Therefore, a series of inference and analysis based on this sample may not be completely objective in describing the whole picture of the formation mechanism of the virtual agglomeration of creative industries. Second, this study confirmed five factors and three mechanisms driving the formation of the virtual agglomeration of creative industries. However, the impact of subdivision dimensions of each factor on the formation of the virtual agglomeration of creative industries has not been measured. Finally, this research was conducted in the virtual agglomeration environment of the Chinese creative industries. Whether the research conclusions are universally relevant to Western creative industries needs to be verified. The research limitations mentioned in this section also point out the direction for future research.

Author Contributions: All authors contributed to the paper. Conceptualization, X.C. and C.L.; Software, Y.J.; Supervision, C.G.; Writing—original draft, X.C.; Writing—review and editing, Y.J. All authors have read and agreed to the published version of the manuscript.

Funding: The research was supported by the National Natural Science Foundation of China (nos. 71874027 and 71704102) and the China Scholarship Council (no. 202006630092).

Institutional Review Board Statement: Not applicable.

Informed Consent Statement: Not applicable.

Data Availability Statement: Data will be available on request from corresponding author.

Conflicts of Interest: The authors declare no conflict of interest. 


\section{References}

1. Aslesen, H.W.; Martin, R.; Sardo, S. The virtual is reality! On physical and virtual space in software firms' knowledge formation. Entrep. Reg. Dev. 2019, 31, 669-682. [CrossRef]

2. Mason, C.; Castleman, T.; Parker, C. Communities of enterprise: Developing regional SMEs in the knowledge economy. J. Enterp. Inf. Manag. 2008, 21, 571-584. [CrossRef]

3. Salvador, E.; Mariotti, I.; Conicella, F. Science park or innovation cluster? Int. J. Entrep. Behav. Res. 2013, 19, 656-674. [CrossRef]

4. Fu, H.; Yeh, H.; Ma, R. A study of the CSFs of an e-cluster platform adoption for microenterprises. Inf. Technol. Manag. 2018, 19, 231-243. [CrossRef]

5. Feng, P. Research on Organizational Evolution in the Big Data Era. Economist 2018, 3, 57-62. [CrossRef]

6. Nucciarelli, A.; Li, F.; Fernandes, K.J.; Goumagias, N.; Cabras, I.; Devlin, S.; Kudenko, D.; Cowling, P. From value chains to technological platforms: The effects of crowdfunding in the digital game industry. J. Bus. Res. 2017, 78, 341-352. [CrossRef]

7. Zhou, J.; Zhang, S. Analysis of the development model of cultural and creative industries under "Internet Plus". Mod. Econ. Res. 2017, 3, 73-77. [CrossRef]

8. Jin, Y.; Pan, J. Platform Leadership and User Entrepreneurship Synergy Model Based on Embedded Open Innovation. China Ind. Econ. 2014, 2, 148-160. [CrossRef]

9. Du, Y.; Xu, C.; Wu, J. Exploring the construction framework of my country's animation industry virtual cluster. Sci. Technol. Manag. Res. 2009, 29, 168-170.

10. Xie, X.; Zang, Z. Ecological governance of network culture industry under the background of "Internet Plus". Sci. Res. Manag. 2016, 37, 80-89.

11. Li, H.; Quan, H. Research on Tourism Virtual Industry Cluster Based on Big Data Platform. Econ. Manag. 2018, 40, 21-38.

12. Glaser, B.G.; Strauss, A.L. The Discovery of Grounded Theory; Strategies for Qualitative Research; Adeline: New York, NY, USA, 1967.

13. Martin, P.Y.; Turner, B.A. Grounded theory and organizational research. J. Appl. Behav. Sci. 1986, 22, 141-157. [CrossRef]

14. Aldiabat, K.M.; Le Navenec, C.L. Data saturation: The mysterious step in grounded theory methodology. Qual. Rep. 2018, 23, 245-261.

15. Xiong, L.; Ji, J.; Chen, P. Dynamic mechanism design: The collaborative innovation in digital content industry based on platform economics. Sci. Technol. Manag. Res. 2016, 36, 21-25.

16. Park, S.C. The fourth industrial revolution and implications for innovative cluster policies. AI Soc. 2017, 33, 433-445. [CrossRef]

17. Nambisan, S. Digital entrepreneurship: Toward a digital technology perspective of entrepreneurship. Entrep. Theory Pract. 2017, 41. [CrossRef]

18. Yan, W.; Chiou, S. Dimensions of Customer Value for the Development of Digital Customization in the Clothing Industry. Sustainability 2020, 12, 4639. [CrossRef]

19. Günther, W.A.; Mehrizi, M.H.R.; Huysman, M.; Feldberg, F. Debating big data: A literature review on realizing value from big data. J. Strateg. Inf. Syst. 2017, 26, 191-209. [CrossRef]

20. Addo, P.M.; Guegan, D.; Hassani, B. Credit risk analysis using machine and deep learning models. Risks 2018, 6, 38. [CrossRef]

21. Dai, Y.; Dai, B. User Experience Evaluation of Public Digital Culture Service Platform in China: A Case Study of National Digital Culture Network Documentation. Inf. Knowl. 2019, 5, 80-89. [CrossRef]

22. Chen, C.; Hung, S. To give or to receive? Factors influencing members' knowledge sharing and community promotion in professional virtual communities. Inf. Knowl. 2010, 47, 226-236. [CrossRef]

23. $\mathrm{Wu}, \mathrm{B}$. Research on operation mechanism of business ecosystem of creative design platform enterprises. J. Natl. Acad. Art 2017, $38,110-116$.

24. Komninos, N.; Kakderi, C.; Collado, A.; Papadaki, I.; Panori, A. Digital Transformation of City Ecosystems: Platforms Shaping Engagement and Externalities across Vertical Markets. J. Urban Technol. 2020, 1-22. [CrossRef]

25. Montero, J.J.; Finger, M. Platformed! Network industries and the new digital paradigm. Compet. Regul. Netw. Ind. 2018, 18, 217-239. [CrossRef]

26. Kostakis, V.; Latoufis, K.; Liarokapis, M.; Bauwens, M. The convergence of digital commons with local manufacturing from a degrowth perspective: Two illustrative cases. J. Clean Prod. 2018, 197, 1684-1693. [CrossRef]

27. Rai, A.; Constantinides, P.; Sarker, S. Editor's comments: Next-generation digital platforms: Toward human-AI hybrids. MIS Q 2019, 43, 3-10.

28. Gareev, T.R. Platform Markets: Their Place in the Theory of Mesoeconomic System: Development and a Challenge to Spatial Studies. Baltic Reg. 2018, 10, 26-38. [CrossRef]

29. Qi, Y.; Xiao, X. Transformation of Enterprise Management in the Era of Digital Economy. Manag. World 2020, 36, 135-152.

30. Zhu, K.; Zhou, J. Research on Virtual Community Governance from the Perspective of Body Sociology. Soc. Sci. Guangxi 2020, 36, 74-77.

31. Fan, Z. The Revolution in Creativity in the Digital Economy; The Comemercial Press: Beijing, China, 2019.

32. Gong, H.; Xin, X. Buzz and tranquility, what matters for creativity? A case study of the online games industry in Shanghai. Geoforum 2019, 106, 105-114. [CrossRef]

33. Guan, W.; Qiao, L.; Chen, K. Dissemination of Marine History and Culture Based on Virtual Museum Technology. J. Coast. Res. 2020, 150-153. [CrossRef]

34. Zemtsov, S. New technologies, potential unemployment and "nescience economy" during and after the 2020 economic crisis. Reg. Sci. Policy Pract. 2020, 12, 723-743. [CrossRef] 
35. Wei, W.; He, Z.; Rayman-Bacchus, L.; Xiang, G. Do Industrial Clusters Still Matter to Trust-Building in the Internet Era? A Network Embeddedness Perspective. SAGE Open 2019, 9. [CrossRef]

36. Peng, B.; Zhang, Q. The formation and evolution of China's internet governance model from 1994 to 2019. J. Commun. 2019, $27,44-65$.

37. Pijls, R.; Groen, B.H.; Galetzka, M.; Pruyn, A.T.H. Measuring the experience of hospitality: Scale development and validation. Int. J. Hosp. Manag. 2017, 67, 125-133. [CrossRef]

38. Sarstedt, M.; Ringle, C.M.; Smith, D.; Reams, R.; Hair, J.F., Jr. Partial least squares structural equation modeling (PLS-SEM): A useful tool for family business researchers. J. Fam. Bus. Strateg. 2014, 5, 105-115. [CrossRef]

39. Hair, J.F., Jr.; Matthews, L.M.; Matthews, R.L.; Sarstedt, M. PLS-SEM or CB-SEM: Updated guidelines on which method to use. Int. J. Multivar. Data Anal. 2017, 1, 107-123. [CrossRef]

40. Chin, W.W.; Dibbern, J. An introduction to a permutation based procedure for multi-group PLS analysis: Results of tests of differences on simulated data and a cross cultural analysis of the sourcing of information system services between Germany and the USA. In Handbook of Partial Least Squares; Springer: Berlin/Heidelberg, Germany, 2010; pp. 171-193.

41. Hair, J.F.; Ringle, C.M.; Sarstedt, M. Partial least squares structural equation modeling: Rigorous applications, better results and higher acceptance. Long Range Plann. 2013, 46, 1-12. [CrossRef]

42. Hair, J.F., Jr.; Hult, G.T.M.; Ringle, C.; Sarstedt, M. A Primer on Partial Least Squares Structural Equation Modeling (PLS-SEM); CA Sage: Thousand Oaks, CA, USA, 2017.

43. Dijkstra, T.K.; Henseler, J. Consistent and asymptotically normal PLS estimators for linear structural equations. Comput. Stat. Data Anal. 2015, 81, 10-23. [CrossRef]

44. Roldán, J.L.; Sánchez-Franco, M.J. Variance-Based structural equation modeling: Guidelines for using partial least squares in information systems research. In Research Methodologies, Innovations and Philosophies in Software Systems Engineering and Information Systems; IGI Global: Hershey PA, USA, 2012; pp. 193-221.

45. Straub, D.; Boudreau, M.C.; Gefen, D. Validation guidelines for IS positivist research. Commun. Assoc. Inf. Syst. 2004, 13, 24. [CrossRef]

46. Fornell, C.; Larcker, D.F. Evaluating structural equation models with unobservable variables and measurement error. J. Mark. Res. 1981, 18, 39-50. [CrossRef]

47. Barclay, D.; Higgins, C.; Thompson, R. The partial least squares (PLS) approach to casual modeling: Personal computer adoption ans use as an Illustration. Technol. Stud. 1995, 2, 285-309.

48. Tehseen, S.; Ramayah, T.; Sajilan, S. Testing and controlling for common method variance: A review of available methods. J. Manag. Sci. 2017, 4, 142-168. [CrossRef]

49. Falk, R.F.; Miller, N.B. A Primer for Soft Modeling; University of Akron Press: Akron, OH, USA, 1992.

50. Xie, X.; Xie, X.; Martinez-Climent, C. Identifying the factors determining the entrepreneurial ecosystem of internet cultural industries in emerging economies. Int. Entrep. Manag. J. 2019, 15, 503-522. [CrossRef]

51. Li, L.; Zhao, X.; Jian, Z. Operation strategy of platform enterprises in network environments. J. Manag. Sci. China 2016, 19, 15-33.

52. Chen, W.; Yu, Z. Platform Strategy; China CITIC Press: Beijing, China, 2013.

53. Hu, D.; Heng, R.; Guo, J. Simulation Research on the Subsidies Promotion Strategy of O2O E-business Platform. Soft Sci. 2016, 30, 96-103.

54. Parc, J.; Kim, S.D. The Digital Transformation of the Korean Music Industry and the Global Emergence of K-Pop. Sustainability 2020, 12, 7790. [CrossRef]

55. Olsson, H.H.; Bosch, J. Going digital: Disruption and transformation in software-intensive embedded systems ecosystems. J. Softw. Evol. Proc. 2020, 32, e2249. [CrossRef]

56. Peukert, C. The next wave of digital technological change and the cultural industries. J. Cult. Econ. 2019, 43, 189-210. [CrossRef]

57. Ren, H.; Wang, R.; Zhang, S.; Zhang, A. How Do Internet Enterprises Obtain Sustainable Development of Organizational Ecology? A Case Study of LeEco Using Institutional Logic Theory. Sustainability 2017, 9, 1375. [CrossRef]

58. Hänninen, M.; Smedlund, A.; Mitronen, L. Digitalization in retailing: Multi-Sided platforms as drivers of industry transformation. Balt. J. Manag. 2018, 13, 152-168. [CrossRef]

59. Aksoy, A.; Ozturk, N. Design of an intelligent decision support system for global outsourcing decisions in the apparel industry. J. Text. Inst. 2016, 107, 1322-1335. [CrossRef]

60. Zhang, T. Development of Library Digital Cultural Creation: Status Quo, Problems and Countermeasures. Res. Libr. Sci. 2020, 27-33. [CrossRef]

61. Deng, W. Creative Environment of French Cultural and Creative Industries in Digital Age. J. Shenzhen Univ. 2014, 31, 141-145.

62. Lazzeretti, L. What is the role of culture facing the digital revolution challenge? Some reflections for a research agenda. Eur. Plan. Stud. 2020, 1-21. [CrossRef]

63. Pagan, E.A.; Salvatella, M.D.G.; Pitarch, M.D.; Munoz, A.L.; Toledo, M.D.M.; Ruiz, J.M.; Vitella, M.; Lo Cicero, G.; Rottensteiner, F.; Clermont, D.; et al. From Silk to Digital Technologies: A Gateway to New Opportunities for Creative Industries, Traditional Crafts and Designers. The SILKNOW Case. Sustainability 2020, 12, 8279. [CrossRef]

64. Jing, W. The Development and Transformation Path of National Cultural Industries During the "Internet Plus" Era. Agro Food Ind. Hi Tech 2017, 28, 2812-2816.

65. Wang, Y. Digitalization is an important support for the modernization of government governance. Governance 2020, 3-7. [CrossRef]

66. Tsai, H.; Lee, H.; Yu, H. Developing the Digital Content Industry in Taiwan. Rev. Policy Res. 2008, 25, 169-188. [CrossRef] 